Invited review

\title{
Optogenetic and chemogenetic therapies for epilepsy
}

\author{
Matthew C. Walker*, Dimitri M. Kullmann \\ Department of Clinical and Experimental Epilepsy, UCL Queen Square Institute of Neurology, London, WC1N 3BG, UK
}

\section{H I G H L I G H T S}

- Gene therapy is a novel effective treatment approach to drug-resistant epilepsy.

- Optogenetics and chemogenetics are titratable therapies.

- Optogenetics can be used in a closed loop treatment paradigm.

- Chemogenetics makes use of endogenous proteins, facilitating translation.

- Invertebrate glutamate receptors offer a novel way to inhibit seizures.

\section{A R T I C L E I N F O}

\section{Keywords:}

DREADD

Optogenetics

Epilepsy

Glutamate-gated chloride channels

PSAM

\begin{abstract}
A B S T R A C T
Drug-resistant epilepsy remains a significant health-care burden. The most effective treatment is surgery, but this is suitable for very few patients because of the unacceptable consequences of removing brain tissue. In contrast, gene therapy can regulate neuronal excitability in the epileptic focus whilst preserving function. Optogenetics and chemogenetics have the advantage that they are titratable therapies. Optogenetics uses light to control the excitability of specific neuronal populations. Optogenetics can be used in a closed-loop paradigm in which the light source is activated only when seizures are detected. However, expression of foreign proteins raises concerns about immunogenicity.

Chemogenetics relies on the modification of an endogenous receptor or the production of a modified chimeric receptor that responds to an exogenous ligand. The main chemogenetic approach applied to epilepsy is to use designer receptors exclusively activated by designer drugs (DREADDs), which have been mainly modified muscarinic receptors or kappa-opioid receptors. Genetically modified human muscarinic receptor DREADDs are activated not by acetylcholine but by specific drugs such as clozapine-n-oxide or olanzepine. The dose of the drugs can be titrated in order to suppress seizures without adverse effects.

Lastly, there is a chemogenetic approach that is activated by an endogenous ligand, glutamate. This takes advantage of invertebrate glutamate receptors that are chloride permeable. These bind glutamate released during seizure activity, and the resultant chloride current inhibits neuronal activity. The exogenous ligand, ivermectin, can also be given to reduce neuronal activity either chronically or as a rescue medication. The translation of this technology is hampered by the expression of a foreign protein.
\end{abstract}

\section{Introduction}

Gene therapy was first conceived as the replacement of a defective gene, using active or inactive viruses or virus-like particles carrying the "healthy" DNA (Friedmann and Roblin, 1972). However, the conditions for which such an approach is suitable are individually relatively rare. Moreover, initial clinical trials resulted in deaths from the (re)activation of the virus used as the vector or immune reactions against the viral vector (Romano, 2006), and this held back gene therapy development. However, advances in viral vector technology have enabled safe and effective methods of transfecting cells, and this has led to an explosion of gene therapy trials. ClinicalTrials.gov lists over 2000 active or completed gene therapy trials and such therapy has expanded from replacing defective genes to overexpressing or "knocking down" healthy genes in order to treat disease. Nevertheless, gene therapy in diseases of the central nervous system has lagged behind treatment of other organs, with only a handful of therapies in clinical trial - most aimed at monogenic brain or spinal cord diseases. Nevertheless, trials for Parkinson's disease go back over 10 years, but all, thus far, have had limited success (Olanow, 2014).

\footnotetext{
* Corresponding author.

E-mail address: m.walker@ucl.ac.uk (M.C. Walker).
} 
Epilepsy would seem an ideal condition for gene therapy. Approximately $30-40 \%$ of people with epilepsy are drug-resistant, and new drugs have had little impact on this number (Chen et al., 2018). Because refractory epilepsy is often focal (Semah et al., 1998), the best hope for an effective treatment is resective surgery. However, this is suitable for fewer than 5\% (Lhatoo et al., 2003), mainly because of concerns regarding the adverse effects of such surgery (Fois et al., 2016; Jetté et al., 2016).

The canonical view is that focal seizures are generated by an imbalance of excitation and inhibition (Wiechert and Herbst, 1966), and that redressing that imbalance will prevent seizure generation (however see section 3 below). Gene therapy is one approach to achieve this and could, therefore, represent an alternative to resective surgery, so that the behavior of neurons in the focus is modified to prevent seizures without disrupting physiological function. This would be ideally suited to foci that are not presently resected because of involvement of eloquent cortex (cortex necessary for crucial functions such as movement, vision and speech). Moreover, gene therapy could be applied to a more distributed network, perhaps even improving upon the success rate of epilepsy surgery (Tracy and Doucet, 2015). Gene therapy in epilepsy has yet to translate to clinical trials, although a number of strategies have been shown to be effective in preclinical models. These strategies have mostly consisted of overexpressing inhibitory peptides such as galanin or NPY (Haberman et al., 2003; Noè et al., 2008; Woldbye et al., 2010) or dampening neuronal excitability in principal cells using overexpression of potassium channels (Snowball et al., 2019; Wykes et al., 2012).

These therapies consist of injection of the vector into the focus where the gene of choice is then expressed in specific cell types depending upon the tropism of the vector and the promoter used. Although some of these approaches are ripe for clinical translation (Kullmann et al., 2014), they are hampered by problems of dose. Once the therapy has been given, the gene dose, expression of that gene and the distribution of the transfected cells are fixed. This could lead to under- or over-dosing. A potential solution to this problem is to express proteins that can be regulated by drugs or light, using chemogenetics or optogenetics. In this way, the therapeutic effect can be adjusted in order to achieve an optimal degree of modulation of circuit excitability. If a deleterious effect on normal brain function is seen, the ligand (drug or light) can be discontinued. Conversely, if a therapeutic effect is only required for a defined duration, for instance in patients who experience clusters of seizures, the ligand can only be used when required. A further application of chemogenetic and optogenetic treatments is to couple delivery of the ligand/light in a closed loop to the detection of a seizure or electrographic signature of an impending seizure. We consider the tools available to implement such treatments below, as well as a further application of chemogenetics that responds to an endogenous ligand, obviating the need for an exogenous drug or light-delivery device.

\section{Viral vectors and promoters}

The growth of gene therapy in medicine has been largely driven by the development of safe and effective means of gene delivery. This has predominantly centred around viral vectors. Viruses have evolved to be incredibly effective carriers of genetic material that can infect cells, "hijack" cellular machinery to transport their DNA to the nucleus or use their RNA as a template to make DNA, and then replicate within the cell. Viruses consist of a protein capsid and, in some, a lipid envelope, and the cargo (the viral DNA or RNA). Viral vectors have the genetic instructions for replication removed and replaced with a desired cargo, typically in order to express or overexpress a specific gene(s) within the cell (Choudhury et al., 2017; Simonato et al., 2013). Viral vectors can also be used to deliver non-coding RNA or gene-editing machinery, but these applications will not be considered further here.

Vectors differ depending on whether they carry DNA or RNA with a reverse transcriptase and on their capsid/envelope (Hudry and Vandenberghe, 2019). Early viral vectors were derived from adenoviruses which can carry a large amount of genetic material, but the adenovirus capsid is particularly immunogenic, contributing to adverse events in clinical trials (Wilson, 2009). Currently-used viral vectors lack immunogenicity and, in neurological disease, adeno associated viruses (AAV, single stranded DNA viruses), lentiviruses (RNA viruses with reverse transcriptase) and herpes simplex viruses (HSV, double stranded DNA viruses) are the basis for most of the vectors used (Choudhury et al., 2017; Simonato et al., 2013). AAV vectors do not have a lipid envelope but the capsid has very low immunogenicity. The capsid binds to a cell surface receptor and different AAV serotypes bind to different cell surface proteins and so have tropism for different cell types within the CNS (Davidson et al., 2000). AAV-delivered DNA forms episomes and minimally integrates with host DNA (Hudry and Vandenberghe, 2019). Depending upon serotype, they can spread to differing extents and they can even be given peripherally crossing into the brain across the blood-brain barrier (Foust et al., 2009) or where there is a deficit in the blood-brain barrier (such as induced by seizures or artificially with focussed ultrasound) (Gray et al., 2010; Stavarache et al., 2018). Extensive research on recombinant capsids has led to the development of AAV variants with other properties, such as the ability to cross the blood-brain barrier when administered systemically (Hudry and Vandenberghe, 2019). Neutralising antibodies against AAVs can be triggered by exposure to therapeutic AAVs, and some humans have preexisting antibodies. However, this appears to be less important in determining the efficacy of AAVs to deliver transgenes in the CNS than in other tissues (Hudry and Vandenberghe, 2019). AAVs would seem the ideal vectors for the CNS, except that they can only carry a small amount of genetic material ( $4.5 \mathrm{~kb})$. Lentiviruses can carry up to $9 \mathrm{~kb}$. They have a lipid envelope and this property together with their size (approximately $100 \mathrm{~nm}$, compared to $20 \mathrm{~nm}$ for AAV) severely restricts the extent of spread of lentiviruses following injection into the brain (Choudhury et al., 2017). This could be an advantage when the target is very close to regions that are critical for normal brain functions. Most lentiviruses lead to DNA integration into the host genome and there is, in principle, a risk of insertional mutagenesis. However, whether this limits their use in the CNS is unclear because neurons are post-mitotic. There are also, now, non-integrating lentiviruses which lead to stable expression of DNA that remains as episomes, so avoiding this theoretical risk (Yáñez-Muñoz et al., 2006). Lastly, there has been increasing preclinical use of HSV vectors. These are even larger $(200 \mathrm{~nm})$, and exist as replicating, replication-deficient and amplicon vectors (lacking all but the packaging viral DNA) (Simonato et al., 2013). The replication and replication-deficient vectors are potentially cytotoxic, although novel strategies are being developed to overcome this (Artusi et al., 2018). The HSV amplicon has a lipid envelope, is strongly neurotropic, and forms episomes. Its main advantage is the ability to carry up to $150 \mathrm{~kb}$ DNA (Choudhury et al., 2017). The main disadvantages are difficulties in amplicon production with cross-contamination from helper viruses, potentially leading to cytotoxicity and immunogenicity (Artusi et al., 2018).

Having chosen a suitable vector, it is necessary to choose the promoter. This will largely determine the cell type in which there is expression. In addition, different promoters will generate different degrees of expression. Although high levels of protein expression would seem desirable, very high expression can lead to endoplasmic reticulum stress and even be cytotoxic, and a suitable balance needs to be struck. Non-specific promoters such as the CMV (cytomegalovirus) promoter or the synthetic CAG promoter based on the chicken beta-actin gene promoter with a CMV enhancer can drive high levels of gene expression, whilst many of the cell-specific promoters are much weaker (Fitzsimons et al., 2002). The elongation factor-1 $\alpha$ (EF-1 $\alpha$ ) promoter is used widely to achieve intermediate levels of expression, whilst the human synapsin (hSyn) promoter is useful to restrict expression to neurons (Kügler et al., 2003). The CaMKII promoter is a reliable 

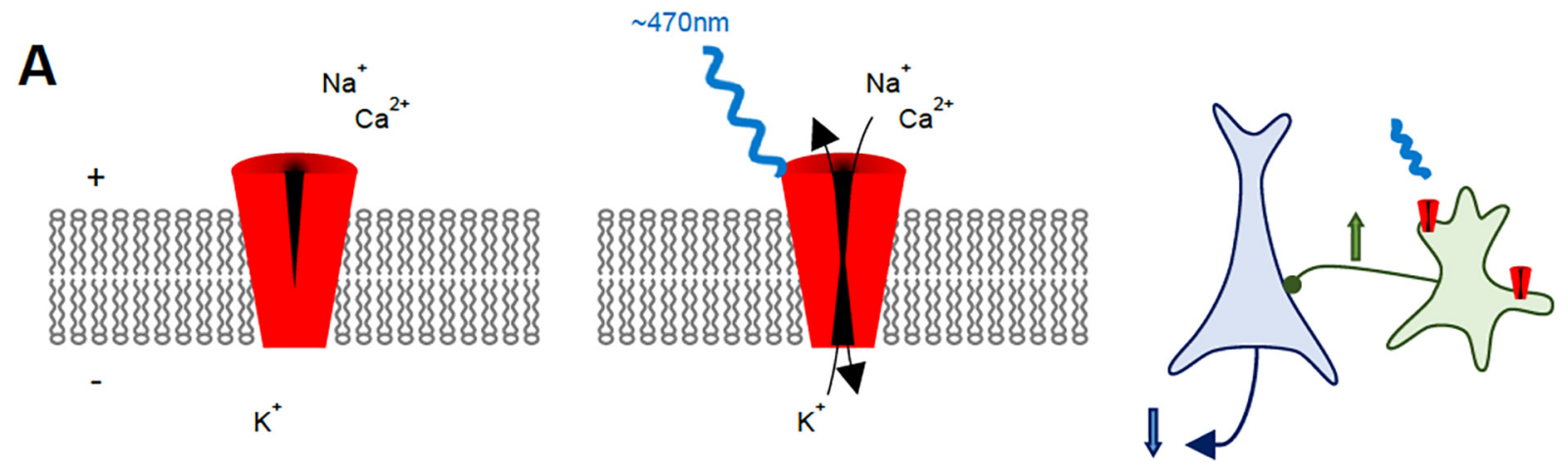

B
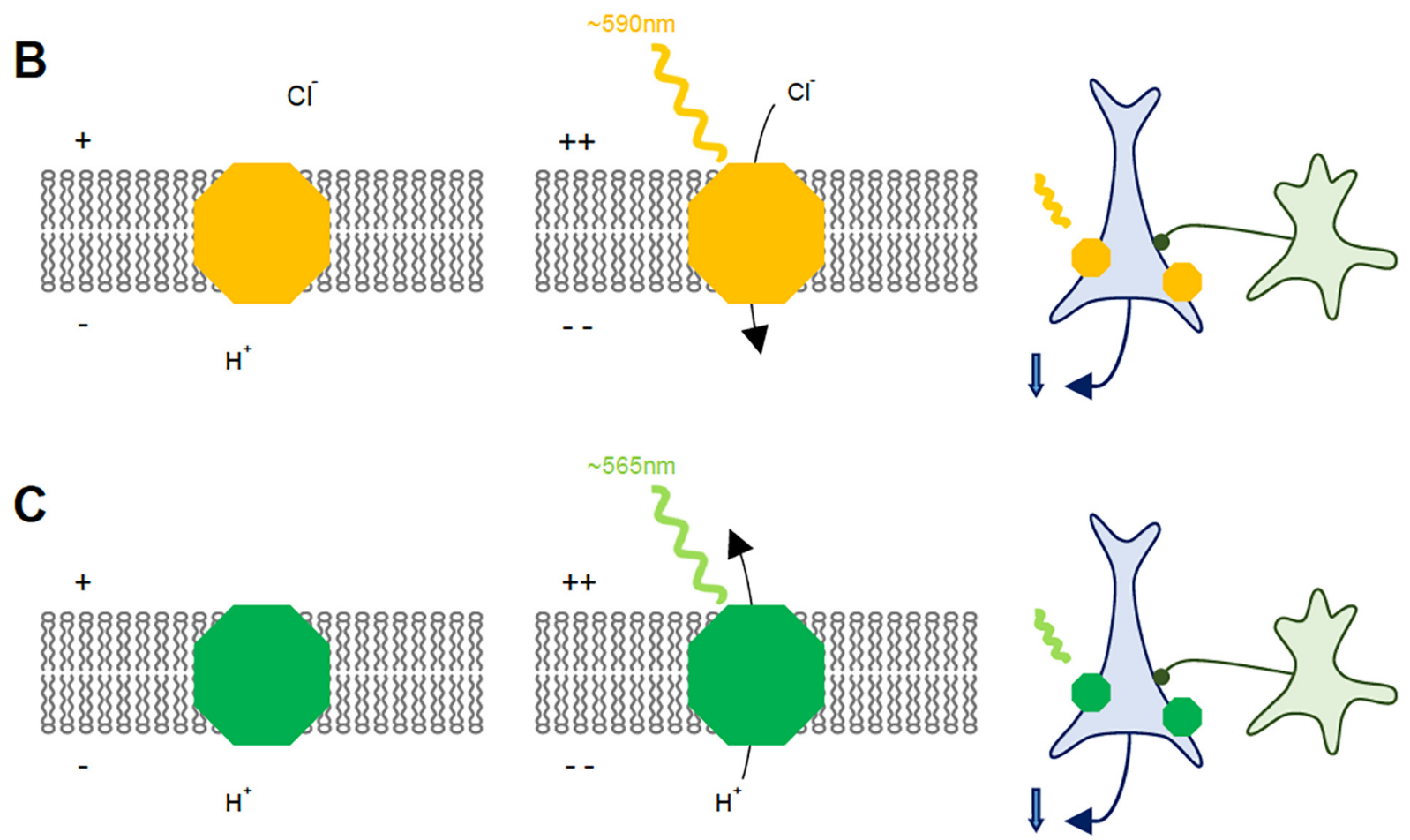

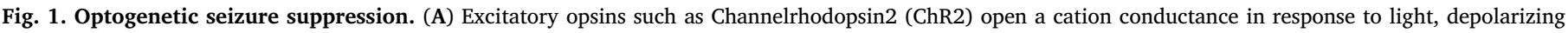

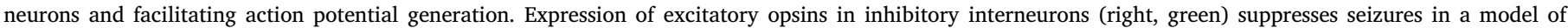

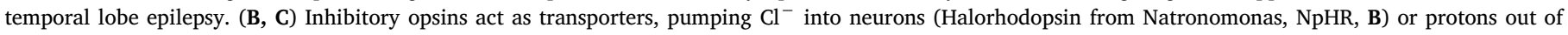
neurons (Archaerhodopsin, Arch, C). When expressed in principal neurons, activation suppresses seizures.

promoter for driving expression in forebrain and hippocampal excitatory neurons (Snowball et al., 2019; Yaguchi et al., 2013). Restricting expression to inhibitory interneurons can be achieved using the mDlx enhancer (Dimidschstein et al., 2016), although, alone, it is not specific to interneuronal subtypes.

\section{Optogenetics}

Francis Crick's wish that there "would a method by which all neurons of just one type could be inactivated, leaving the others more or less unaltered" (Crick, 1979) was realised by Gero Miesenböck, whose laboratory first genetically expressed opsins in specific groups of neurons to alter fly behavior (Lima and Miesenböck, 2005). Later, Karl Deisseroth and Ed Boyden used Channelrhodopsin2 (ChR2), a blue light-activated cation channel derived from algae (Fig. 1) (Nagel et al., 2003), to excite specific subsets of mammalian neurons with millisecond precision (Boyden et al., 2005). These opsins depend upon the transfected cell producing the chromophore retinal, which binds to the opsin (Nagel et al., 2003); it was surprising that neurons synthesized sufficient retinal for this strategy to work. However, the establishment of these methods led to an explosion of opsin development, including the use of opsins from archaea (Fig. 1) - halorhodopsin (NpHR, a hyperpolarizing chloride pump) (Zhang et al., 2007) and archaerhodopsin (a hyperpolarizing proton pump) (Chow et al., 2010) - and alterations to opsins so that they responded to different wavelengths of light or had different kinetics. Channelrhodopsins have also been altered to operate as bistable (step-function) channels requiring light to switch them from one state to another, so that continuous light administration is unnecessary to maintain a current (Berndt et al., 2009). More recently, ChR2 has been engineered to have an anion conductance and so to act as an inhibitory channel (Berndt et al., 2014).

Optogenetics would seem an ideal means of regulating epileptogenic circuits as, using these tools, it is possible to regulate selectively inhibitory or excitatory neuronal behavior. The most appealing strategies are to excite inhibitory neurons with a cation-permeable opsin such as ChR2 or to inhibit excitatory neurons with an anion-permeable opsin such as NpHR.

The first successful "treatment" of in vitro seizure activity was through the activation of NpHR expressed in excitatory cells in the hippocampus using a lentiviral vector and the CaMKII promotor, 
limiting expression of NpHR to excitatory neurons (Tønnesen et al., 2009). These results were reproduced in an in vivo model of continuous motor seizure activity (modelling the human condition epilepsia partialis continua) (Wykes et al., 2012). These seizures are particularly resistant to systemic drug treatment, yet activation of $\mathrm{NpHR}$ in the focus inhibited seizure activity (Wykes et al., 2012). These studies provided the first proof-of-principle of the potential of optogenetics as a therapy in epilepsy.

Optogenetics has not only given us a new treatment approach but also a way of dissecting out the networks generating and regulating seizure activity. In a neocortical stroke model, inhibiting thalamocortical neurons with NpHR stopped spike-wave discharges in the cortex (Paz et al., 2013), and in a model of limbic epilepsy, either inhibiting excitatory neurons with NpHR or activating parvalbumin-expressing interneurons with ChR2 inhibited hippocampal seizures (KrookMagnuson et al., 2013). Limbic seizures could also be modulated by stimulating relatively remote structures such as the cerebellum with optogenetics (Krook-Magnuson et al., 2014). Indeed, optogenetics offers a much more precise way to modulate neurons within a brain area. Current electrical methods of brain stimulation in epilepsy not only affect excitatory and inhibitory neurons indiscriminately within an area but also can antidromically recruit neurons distant from the stimulation area and can affect axons nearby. High stimulation frequencies, moreover, can silence a network through a variety of mechanisms. It is not surprising, therefore, that the mechanisms underlying the efficacy of many forms of brain stimulation in epilepsy are incompletely understood, and present brain stimulation protocols are likely sub-optimal (Boon et al., 2009). Optogenetics gives us the opportunity of addressing these problems and of developing more precise means of brain stimulation.

However, from a translational perspective, the most exciting aspect of optogenetics is the ability to use a closed-loop system in which an implanted EEG device detects the beginning of the seizure which triggers a light-emitting device, activating the opsin expressed within specific classes of neurons. Such closed -loop systems have been used successfully to halt seizure activity using intracranial and transcranial electrical stimulation (Berényi et al., 2012; Morrell, 2011), but these lack the specificity available to optogenetic approaches. Closed-loop optogenetic approaches have been successfully used to halt seizure activity in the cortex by inhibiting thalamocortical neurons, and in the hippocampus by inhibiting local pyramidal cells, exciting local parvalbumin-containing interneurons, or activating remote cerebellar Purkinje cells (Krook-Magnuson et al., 2014, 2013; Paz et al., 2013).

Such an on-demand tool that can rapidly alter network activity would seem an ideal method to treat paroxysmal rapid changes in network behavior characteristic of seizures, but significant problems are emerging. These fall into three categories: practical problems, biological problems and functional problems. There is the purely practical problem of getting the gene therapy, light source and electrodes into the appropriate places in the brain. Light is both absorbed and scattered (the degree depending upon wavelength) in the brain, so that light energy rapidly decreases with distance from the source, limiting the volume of brain in which opsins can be activated. Solutions to this problem have mainly consisted of modifying the design of LEDs and lasers, as well as optical fibers, but these are invasive, require electrical circuits that may fail, and can heat the tissue if not appropriately calibrated (Owen et al., 2019). Moreover, even small degrees of tissue heating can affect neuronal behavior (Owen et al., 2019). The reliable detection of seizures also remains a problem, although an ever-expanding number of solutions are being developed (Baldassano et al., 2017). The rapid detection of seizures is necessary, not least because, as seizures progress, they involve larger and more distributed networks and so are unlikely to be stopped by targeting a small volume of brain. Biological problems largely center around the fact that the opsins that are used in optogenetics are foreign proteins and long-term expression of foreign proteins in the brain raises the concern of immunogenicity.
The brain has traditionally been considered to be immunoprivileged, but the discovery of a range of CNS diseases associated with autoantibodies to membrane proteins has largely challenged this concept (Carson et al., 2006), and the ethics of introducing a foreign protein into the brain are a significant hurdle. Lastly there are the functional problems. Optogenetics has opened up not only a route to novel treatments but also our eyes to the complexity of neuronal and network behavior. The inhibitory opsins that have largely been used are pumps that actively change the internal milieu. For example, activation of NpHR will increase the internal chloride concentration and so depolarize the reversal potential for chloride (Alfonsa et al., 2015; Sørensen et al., 2017). This could consequently lead to a post-treatment outflow of chloride from the cell, depolarizing the neuron, leading to rebound firing. In addition, the change in the chloride reversal potential will directly affect GABA(A) receptor mediated transmission, so that GABA(A) receptor currents could change from hyperpolarizing to depolarizing. An even greater problem, perhaps, is our incomplete understanding of the roles that interneuronal cell populations play in seizure initiation and maintenance. There is evidence that, within the focus, interneuronal activity can facilitate seizure initiation, possibly though synchronizing the network or contributing to local potassium accumulation (Sessolo et al., 2015). In contrast, away from the focus, interneuronal activity can inhibit seizure spread (Sessolo et al., 2015). The role of interneurons may also change during the seizure with early interneuronal activation halting the seizure but late activation having a paradoxical excitatory effect due to chloride accumulation within principal cells, prolonging seizure activity (Magloire et al., 2019).

Together these problems will slow clinical translation but optogenetics is proving to be a critical tool in furthering our understanding of networks, seizures and epilepsy, and even if it does not directly translate into a therapy, it will certainly enable the development of novel approaches to the treatment of epilepsy.

\section{Chemogenetics}

Chemogenetics offers an alternative approach to designing a controllable gene therapy. Chemogenetics is the introduction of an engineered receptor or channel into cells that selectively responds to a small molecule ligand. This technology falls into two broad categories genetically-modified G-protein coupled receptors or chimeric ligandgated receptors. A confounder for clinical translation is the necessity to demonstrate safety of both the gene therapy and the small molecule. One way to mitigate this ethical and financial hurdle is to repurpose a small molecule that is already used clinically and for which there would be ample safety data. This consideration is critical when we come to consider the technologies available.

Chimeric ligand-gated ion channels are exemplified by the pharmacologically selective actuator module/pharmacologically selective effector molecule (PSAM/PSEM) technology developed by Scott Sternson's laboratory (Magnus et al., 2011). The receptor design takes advantage of the conserved pentameric structure of the Cys-loop family which includes nicotinic receptors, serotonin receptor 3, GABA(A) receptors and glycine receptors. The PSAM chimeric receptor consists of the extracellular domains of a mutated $\alpha 7$-nicotinic acetylcholine receptor subunit with the transmembrane and intracellular domains of another Cys-loop receptor - GlyR1 glycine receptor subunit for an inhibitory receptor that is chloride-permeable, and 5HT3 serotonin receptor subunit for an excitatory receptor that is sodium-permeable. The $\alpha 7$-nicotinic acetylcholine receptor subunit is used, as the pharmacology and crystal structure of the acetylcholine binding site are very well characterised, enabling the introduction of specific mutations to confer sensitivity to a selective ligand, termed the pharmacologically selective effector molecule (PSEM). So far, this technology has not been tested in epilepsy models and most of the PSEMs that have been wellcharacterised have significant off-target effects at relevant concentrations and have not been used in humans. Recently a new PSAM has 
been developed that is sensitive to varenicline (Magnus et al., 2019), a drug approved for smoking cessation; however, because varenicline itself is an $\alpha 7$-nicotinic acetylcholine receptor ligand it may not be completely free from side-effects. A further potential disadvantage of this approach is that the maximal response will depend upon the extent of PSAM expression within a neuron, so that low expression will likely lead to a low maximal effect. Moreover, the use of a PSAM permeable to chloride raises the concern of chloride loading, potentially decreasing the efficacy of GABA(A) receptor-mediated inhibition; also changes in the chloride reversal potential, which can occur during epileptogenesis (Miles et al., 2012), may reduce the efficacy of the treatment.

A chemogenetic technology that has been tried in preclinical epilepsy models relies on a mutated muscarinic receptor developed by Bryan Roth and colleagues (Armbruster et al., 2007). The generic term for this tool is Designer Receptors Exclusively Activated by Designer Drugs (DREADDs). The original DREADDs were derived from muscarinic acetylcholine receptors, in which the binding site for acetylcholine has been mutated so that rather than binding acetylcholine, the receptor binds a specific set of drugs. It is possible using this technology to design a receptor which will bind an otherwise biologically inert drug. DREADDs include the hM4D (Gi) inhibitory receptor (Fig. 2), and the hM3Dq excitatory receptor (both are modifications of human muscarinic receptors). There is also a GsD excitatory DREADD, constructed from a rat muscarinic receptor-turkey $\beta 1$-receptor hybrid, and another inhibitory DREADD based around the kappa-opioid receptor (Wess et al., 2013). One potential advantage of this technology is that rather than using a ligand-gated channel, these are G-protein coupled receptors. If expressed at high levels, only a small fraction of the receptors need to be activated to have a maximal down-stream effect (the so-called 'receptor reserve' phenomenon) (Wacker et al., 2017). This means that ligands could potentially be used at very low doses. However, a separate challenge is that G-protein coupled receptors can, over time, desensitize and thus show tachyphylaxis. This is mitigated to a certain extent by receptor reserve so that even if only a few receptors are available, they will still be sufficient for a significant biological effect. Reassuringly, baclofen, a GABA(B) receptor agonist that activates the Gi cascade shows sustained long-term efficacy when used to treat spasticity (Sammaraiee et al., 2019).

We have tested inhibitory DREADDs in both acute and chronic seizure models, including an in vivo model of continuous motor seizure activity (Kätzel et al., 2014), using a DREADD which responds to a lowdose of clozapine-N-oxide, a biologically inert metabolite of clozapine (a drug used in psychiatric disease in humans). We transfected excitatory neurons in the epileptic focus and showed that acute and chronic seizures were ameliorated when clozapine-N-oxide was given, but the gene therapy had no effect in the absence of the drug (Kätzel et al., 2014). The advantage of this system is that the gene therapy is inert until the drug is given, so it is possible to turn the gene therapy "off and on". Moreover, the magnitude of the effect of the DREADD depends upon the dose of the ligand. It is therefore possible to titrate the dose of the drug to avoid any potential side-effects of the DREADD but yet to optimise efficacy. Although promising, recent evidence has emerged that clozapine-N-oxide does not cross the blood-brain barrier and that the effect that we and others have seen is most likely due to back-conversion of clozapine-N-oxide into clozapine followed by transport of clozapine into the brain (Gomez et al., 2017; Manvich et al., 2018). Clozapine is far from optimal as a DREADD agonist, because in addition to its psychiatric effects, it is associated with agranulocytosis and is pro-epileptic in some patients (Ruffmann et al., 2006). We have, therefore, looked for other more appropriate ligands and have found that olanzapine, an antipsychotic which is significantly safer than clozapine, at very low doses can also activate the hM4D (Gi) DREADD, paving the way for clinical trials (Weston et al., 2019).

DREADDs have also been shown to be effective in other epilepsies. Inhibitory DREADDs expressed in principal cells can suppress in vitro seizure activity in an organotypic hippocampal slice culture model of drug-resistant epilepsy (Avaliani et al., 2016), and DREADDs used to silence neurons in the midline and laminar thalamus can suppress and, in some animals, stop amygdala kindled seizures (a model in which repetitive subthreshold stimulation of the amygdala leads to progressively lowered seizure threshold and more severe seizures) (Wicker and Forcelli, 2016).

Others have shown that expressing the excitatory DREADD in inhibitory parvalbumin interneurons is also an effective strategy. In vitro studies have shown suppression of epileptiform activity in the hippocampus (Cǎlin et al., 2018) and in vivo studies have shown an inhibitory effect in the hippocampal kindling model and a significant reduction in the number of spontaneous limbic seizures following in vivo injection of kainic acid into the hippocampi of mice (Wang et al., 2018).

Lastly, in the same way that optogenetics has been used to determine mechanisms in epilepsy, recent work has demonstrated that DREADD-mediated suppression of newborn dentate granule cells can inhibit spontaneous recurrent seizures following pilocarpine-induced status epilepticus; DREADD-mediated activation of these cells increased the occurrence of spontaneous recurrent seizures (Zhou et al., 2019).

Since human muscarinic DREADDs involve limited mutations in the
A
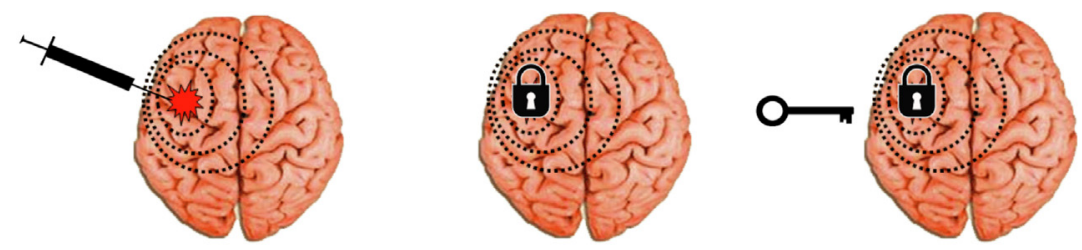

B

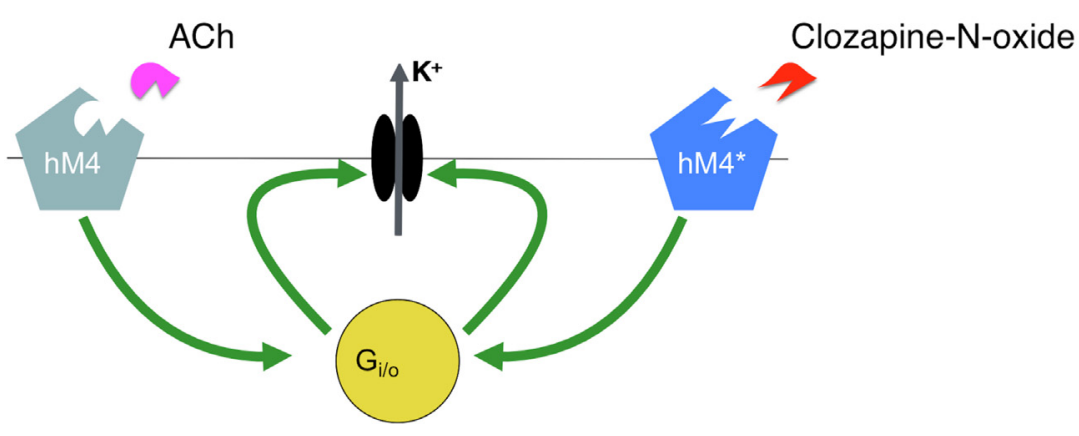

Fig. 2. Inhibitory chemogenetics for treatment of epilepsy. (A) Using the lock-and-key analogy of pharmacology, the gene therapy leads to the expression of an inhibitory receptor (lock), which is inactive until the ligand (key) is administered. (B) A widely used inhibitory DREADD is derived from the human M4 muscarinic receptor (hM4), with two amino acid substitutions making the receptor insensitive to acetylcholine (ACh) and sensitive instead to clozapine-N-oxide, olanzapine and a few other ligands. Activation of the receptor triggers a G-protein cascade that opens inward-rectifying potassium channels. This, together with inhibition of neurotransmitter release, results in suppression of circuit excitability. 


\section{Normal}
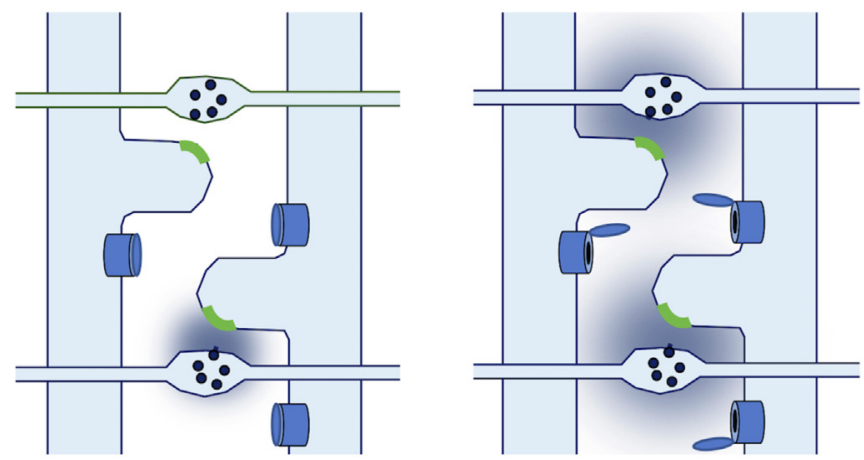

Closed

Open

Fig. 3. Self-regulating chemogenetics: During normal synaptic activity (left) glutamate released from presynaptic boutons activates synaptic receptors. During pathological excessive activity, glutamate released from multiple active synapses overwhelms transporters. Glutamate spillover is then able to activate extrasynaptic inhibitory eGluCl receptors, suppressing circuit excitability.

ligand-binding domain of an endogenous protein, they are unlikely to have immunogenic potential. The receptor reserve phenomenon and the existence of ligands which can be easily repurposed make these approaches very attractive for clinical translation. Moreover, anti-epileptic efficacy and any adverse effects could in principle be traded off by titrating the dose of ligand. DREADDs are ideal for therapeutic approaches in which network excitability needs to be altered over long periods of time. However, the problems of using a drug to turn "off and on" a therapy is that an orally or parenterally delivered drug has to get absorbed and then enter the CNS before it can have an effect. There is, therefore, a delay between giving the drug and its action. This means that the DREADD technology is ideally suited to chronic alterations of network excitability rather than targeting acute seizures. Nevertheless, seizures often cluster and a DREADD could also be used for rescue therapy after a single seizure to prevent seizure clustering or during a prolonged seizure to prevent status epilepticus. Moreover, with improvements in seizure prediction, it may be possible to use rescue therapies to prevent imminent seizures from occurring (Cook et al., 2013). A further possible consideration is the observation that expression of DREADDs in peripheral c-fibers resulted in electrophysiological changes in second messenger signalling and neuronal properties in the absence of the ligand, possibly due to constitutive G-protein activation by the DREADD (Saloman et al., 2016). However, these changes mainly resulted in reduced neuronal excitability, a desired effect. Moreover, we have not observed an effect of DREADD expression alone on rodent behavior.

\section{Self-regulating chemogenetics}

A chemogenetic approach that uses an endogenous ligand instead of a drug takes advantage of the glutamate-gated chloride channel, $\mathrm{GluCl}$, present in invertebrates (including C. Elegans) (Cully et al., 1994). This receptor is also a member of the Cys-loop family and is very different from mammalian ionotropic glutamate receptors. $\mathrm{GluCl}$ is sensitive to ivermectin, which is used clinically as an antiparasitic agent (Campbell, 2016). The receptor is heteropentameric comprising two subunits (GluCla and GluClß), both of which need to be expressed to have a functioning channel (Slimko et al., 2002). Introducing a mutation in the glutamate binding site of GluCl $\alpha$ increases glutamate sensitivity by several orders of magnitude, so that it can detect micromolar concentrations of glutamate, which can occur in the extracellular space (Frazier et al., 2013; Lieb et al., 2018). When this 'enhanced GluCl' (eGluCl) receptor is expressed in excitatory mammalian neurons, it is not inserted into synapses and so does not detect glutamate release at the synapse during normal network activity (Lieb et al., 2018). However, when network activity increases, glutamate escaping from multiple synapses overwhelms transporters and accumulates in the extracellular space where it is able to activate these receptors, inhibiting the excitatory neurons and so dampening down network activity (Fig. 3) (Lieb et al., 2018). Thus, this receptor acts as an endogenous closedloop system. We have shown efficacy in acute and chronic seizure models, and also, importantly, that these receptors have no effect on normal function when expressed in the motor cortex (Lieb et al., 2018).

A further potential advantage of treatment with eGluCl is that it is very sensitive to ivermectin, which acts synergistically with glutamate to activate the receptor and could in principle be used as add-on treatment. Although eGluCl is a very attractive option for chemogenetic treatment of epilepsy, one of the main translational hurdles, as with optogenetics, is that it relies on expression of a non-mammalian protein in the CNS. Also, although chloride accumulation is avoided as the receptors are only activated during excessive neuronal activity, the changes in chloride reversal potential in some epilepsies may make the therapy less effective. The same caveats that may limit the usefulness of chloride-permeable PSAMs mentioned above therefore apply.

\section{Conclusion}

Gene therapy represents one of the most promising ways to address the enormous unmet need represented by refractory epilepsy, especially when resective surgery is too great a risk. Optogenetics and chemogenetics have the distinct advantage over permanent modulation of circuit excitability that their therapeutic effect can be adjusted or even made part of a closed loop system. Of the available tools, DREADDbased inhibition is poised for clinical translation. Although eGluCl expression may remove the need for an exogenous ligand, uncertainties regarding the potential immunogenicity of the receptor would need to be addressed prior to clinical translation.

\section{Funding}

This work detailed here was supported by Epilepsy Research UK, and Medical Research Council program grant (MR/L01095X/1: Gene therapy for refractory epilepsy).

\section{Conflicts of interest}

MCW and DK have a patent "Combined use of a vector encoding a modified receptor and its exogenous agonist in the treatment of seizures".

\section{References}

Alfonsa, H., Merricks, E.M., Codadu, N.K., Cunningham, M.O., Deisseroth, K., Racca, C., Trevelyan, A.J., 2015. The contribution of raised intraneuronal chloride to epileptic network activity. J. Neurosci. 35, 7715-7726. https://doi.org/10.1523/JNEUROSCI. 4105-14.2015.

Armbruster, B.N., Li, X., Pausch, M.H., Herlitze, S., Roth, B.L., 2007. Evolving the lock to fit the key to create a family of $\mathrm{G}$ protein-coupled receptors potently activated by an inert ligand. Proc. Natl. Acad. Sci. 104, 5163-5168. https://doi.org/10.1073/pnas. 0700293104.

Artusi, S., Miyagawa, Y., Goins, W.F., Cohen, J.B., Glorioso, J.C., 2018. Herpes simplex virus vectors for gene transfer to the central nervous system. Diseases 6, 74. https:// doi.org/10.3390/diseases6030074.

Avaliani, N., Andersson, M., Runegaard, A.H., Woldbye, D., Kokaia, M., 2016. DREADDs suppress seizure-like activity in a mouse model of pharmacoresistant epileptic brain tissue. Gene Ther. 23, 760-766. https://doi.org/10.1038/gt.2016.56.

Baldassano, S.N., Brinkmann, B.H., Ung, H., Blevins, T., Conrad, E.C., Leyde, K., Cook, M.J., Khambhati, A.N., Wagenaar, J.B., Worrell, G.A., Litt, B., 2017. Crowdsourcing seizure detection: algorithm development and validation on human implanted device recordings. Brain 140, 1680-1691. https://doi.org/10.1093/brain/awx098. 
Berényi, A., Belluscio, M., Mao, D., Buzsáki, G., 2012. Closed-loop control of epilepsy by transcranial electrical stimulation. Science 337, 735-737. https://doi.org/10.1126/ science.1223154.

Berndt, A., Lee, S.Y., Ramakrishnan, C., Deisseroth, K., 2014. Structure-guided transformation of channelrhodopsin into a light-activated chloride channel. Science 344 420-424. https://doi.org/10.1126/science.1252367.

Berndt, A., Yizhar, O., Gunaydin, L.A., Hegemann, P., Deisseroth, K., 2009. Bi-stable neural state switches. Nat. Neurosci. 12, 229-234. https://doi.org/10.1038/nn.2247.

Boon, P., Raedt, R., de Herdt, V., Wyckhuys, T., Vonck, K., 2009. Electrical stimulation for the treatment of epilepsy. Neurotherapeutics 6, 218-227. https://doi.org/10.1016/j. nurt.2008.12.003.

Boyden, E.S., Zhang, F., Bamberg, E., Nagel, G., Deisseroth, K., 2005. Millisecond-timescale, genetically targeted optical control of neural activity. Nat. Neurosci. 8, 1263-1268. https://doi.org/10.1038/nn1525.

Călin, A., Stancu, M., Zagrean, A.-M., Jefferys, J.G.R., Ilie, A.S., Akerman, C.J., 2018. Chemogenetic recruitment of specific interneurons suppresses seizure activity. Front. Cell. Neurosci. 12, 293. https://doi.org/10.3389/fncel.2018.00293.

Campbell, W.C., 2016. Ivermectin: a reflection on simplicity (nobel lecture). Angew Chem. Int. Ed. Engl. 55, 10184-10189. https://doi.org/10.1002/anie.201601492.

Carson, M.J., Doose, J.M., Melchior, B., Schmid, C.D., Ploix, C.C., 2006. CNS immune privilege: hiding in plain sight. Immunol. Rev. 213, 48-65. https://doi.org/10.1111/ j.1600-065X.2006.00441.x.

Chen, Z., Brodie, M.J., Liew, D., Kwan, P., 2018. Treatment outcomes in patients with newly diagnosed epilepsy treated with established and new antiepileptic drugs: a 30year longitudinal cohort study. JAMA Neurol 75, 279-286. https://doi.org/10.1001/ jamaneurol.2017.3949.

Choudhury, S.R., Hudry, E., Maguire, C.A., Sena-Esteves, M., Breakefield, X.O., Grandi, P., 2017. Viral vectors for therapy of neurologic diseases. Neuropharmacology 120 , 63-80. https://doi.org/10.1016/j.neuropharm.2016.02.013.

Chow, B.Y., Han, X., Dobry, A.S., Qian, X., Chuong, A.S., Li, M., Henninger, M.A., Belfort, G.M., Lin, Y., Monahan, P.E., Boyden, E.S., 2010. High-performance genetically targetable optical neural silencing by light-driven proton pumps. Nature 463, 98-102. https://doi.org/10.1038/nature08652.

Cook, M.J., O'Brien, T.J., Berkovic, S.F., Murphy, M., Morokoff, A., Fabinyi, G., D'Souza, W., Yerra, R., Archer, J., Litewka, L., Hosking, S., Lightfoot, P., Ruedebusch, V., Sheffield, W.D., Snyder, D., Leyde, K., Himes, D., 2013. Prediction of seizure likelihood with a long-term, implanted seizure advisory system in patients with drugresistant epilepsy: a first-in-man study. Lancet Neurol. 12, 563-571. https://doi.org/ 10.1016/S1474-4422(13)70075-9.

Crick, F.H.C., 1979. Thinking about the brain. Sci. Am. 241, 219-233.

Cully, D.F., Vassilatis, D.K., Liu, K.K., Paress, P.S., Van der Ploeg, L.H., Schaeffer, J.M., Arena, J.P., 1994. Cloning of an avermectin-sensitive glutamate-gated chloride channel from Caenorhabditis elegans. Nature 371, 707-711. https://doi.org/10. 1038/371707a0.

Davidson, B.L., Stein, C.S., Heth, J.A., Martins, I., Kotin, R.M., Derksen, T.A., Zabner, J., Ghodsi, A., Chiorini, J.A., 2000. Recombinant adeno-associated virus type 2, 4, and 5 vectors: transduction of variant cell types and regions in the mammalian central nervous system. Proc. Natl. Acad. Sci. 97, 3428-3432. https://doi.org/10.1073/pnas. 97.7.3428.

Dimidschstein, J., Chen, Q., Tremblay, R., Rogers, S., Saldi, G., Guo, L., Xu, C., Liu, R., Lu, C., Chu, J., Avery, M., Rashid, S., Baek, M., Jacob, A., Smith, G., Wilson, D., Kosche, G., Kruglikov, I., Rusielewicz, T., Kotak, V., Mowery, T., Anderson, S., Callaway, E., Dasen, J., Fitzpatrick, D., Fossati, V., Long, M., Noggle, S., Reynolds, J., Sanes, D., Rudy, B., Feng, G., Fishell, G., 2016. A viral strategy for targeting and manipulating interneurons across vertebrate species. Nat. Neurosci. 19, 1743-1749. https://doi. org/10.1038/nn.4430.

Fitzsimons, H.L., Bland, R.J., During, M.J., 2002. Promoters and regulatory elements that improve adeno-associated virus transgene expression in the brain. Methods 28 , 227-236. https://doi.org/10.1016/S1046-2023(02)00227-X.

Fois, C., Kovac, S., Khalil, A., Uzuner, G.T., Diehl, B., Wehner, T., Duncan, J.S., Walker, M.C., 2016. Predictors for being offered epilepsy surgery: 5-year experience of a tertiary referral centre. J. Neurol. Neurosurg. Psychiatry 87, 209-211. https://doi. org/10.1136/jnnp-2014-310148.

Foust, K.D., Nurre, E., Montgomery, C.L., Hernandez, A., Chan, C.M., Kaspar, B.K., 2009. Intravascular AAV9 preferentially targets neonatal-neurons and adult-astrocytes in CNS. Nat. Biotechnol. 27, 59-65. https://doi.org/10.1038/nbt.1515.

Frazier, S.J., Cohen, B.N., Lester, H.A., 2013. An engineered glutamate-gated chloride (GluCl) channel for sensitive, consistent neuronal silencing by ivermectin. J. Biol. Chem. 288, 21029-21042. https://doi.org/10.1074/jbc.M112.423921.

Friedmann, T., Roblin, R., 1972. Gene therapy for human genetic disease? Science 175, 949-955. https://doi.org/10.1126/science.175.4025.949.

Gomez, J.L., Bonaventura, J., Lesniak, W., Mathews, W.B., Sysa-Shah, P., Rodriguez, L.A., Ellis, R.J., Richie, C.T., Harvey, B.K., Dannals, R.F., Pomper, M.G., Bonci, A., Michaelides, M., 2017. Chemogenetics revealed: DREADD occupancy and activation via converted clozapine. Science 357, 503-507. https://doi.org/10.1126/science. aan 2475 .

Gray, S.J., Blake, B.L., Criswell, H.E., Nicolson, S.C., Samulski, R.J., McCown, T.J., Li, W., 2010. Directed evolution of a novel adeno-associated virus (AAV) vector that crosses the seizure-compromised blood-brain barrier (BBB). Mol. Ther. 18, 570-578. https:// doi.org/10.1038/mt.2009.292.

Haberman, R.P., Samulski, R.J., McCown, T.J., 2003. Attenuation of seizures and neuronal death by adeno-associated virus vector galanin expression and secretion. Nat. Med. 9, 1076-1080. https://doi.org/10.1038/nm901.

Hudry, E., Vandenberghe, L.H., 2019. Therapeutic AAV gene transfer to the nervous system: a clinical reality. Neuron 101, 839-862. https://doi.org/10.1016/j.neuron. 2019.02.017.
Jetté, N., Sander, J.W., Keezer, M.R., 2016. Surgical treatment for epilepsy: the potential gap between evidence and practice. Lancet Neurol. 15, 982-994. https://doi.org/10. 1016/S1474-4422(16)30127-2.

Kätzel, D., Nicholson, E., Schorge, S., Walker, M.C., Kullmann, D.M., 2014. Chemicalgenetic attenuation of focal neocortical seizures. Nat. Commun. 5, 3847. https://doi. org $/ 10.1038 /$ ncomms 4847 .

Krook-Magnuson, E., Armstrong, C., Oijala, M., Soltesz, I., 2013. On-demand optogenetic control of spontaneous seizures in temporal lobe epilepsy. Nat. Commun. 4, 1376. https://doi.org/10.1038/ncomms2376.

Krook-Magnuson, E., Szabo, G.G., Armstrong, C., Oijala, M., Soltesz, I., 2014. Cerebellar directed optogenetic intervention inhibits spontaneous hippocampal seizures in a mouse model of temporal lobe epilepsy. eNeuro 1. https://doi.org/10.1523/ ENEURO.0005-14.2014.

Kügler, S., Kilic, E., Bähr, M., 2003. Human synapsin 1 gene promoter confers highly neuron-specific long-term transgene expression from an adenoviral vector in the adult rat brain depending on the transduced area. Gene Ther. 10, 337-347. https:// doi.org/10.1038/sj.gt.3301905.

Kullmann, D.M., Schorge, S., Walker, M.C., Wykes, R.C., 2014. Gene therapy in epilepsyis it time for clinical trials? Nat. Rev. Neurol. 10, 300-304. https://doi.org/10.1038/ nrneurol.2014.43.

Lhatoo, S.D., Solomon, J.K., McEvoy, A.W., Kitchen, N.D., Shorvon, S.D., Sander, J.W., 2003. A prospective study of the requirement for and the provision of epilepsy surgery in the United Kingdom. Epilepsia 44, 673-676. https://doi.org/10.1046/j.15281157.2003.46002.x.

Lieb, A., Qiu, Y., Dixon, C.L., Heller, J.P., Walker, M.C., Schorge, S., Kullmann, D.M., 2018. Biochemical autoregulatory gene therapy for focal epilepsy. Nat. Med. 24, 1324-1329. https://doi.org/10.1038/s41591-018-0103-x.

Lima, S.Q., Miesenböck, G., 2005. Remote control of behavior through genetically targeted photostimulation of neurons. Cell 121, 141-152. https://doi.org/10.1016/j. cell.2005.02.004

Magloire, V., Cornford, J., Lieb, A., Kullmann, D.M., Pavlov, I., 2019. KCC2 overexpression prevents the paradoxical seizure-promoting action of somatic inhibition. Nat. Commun. 10, 1225. https://doi.org/10.1038/s41467-019-08933-4.

Magnus, C.J., Lee, P.H., Atasoy, D., Su, H.H., Looger, L.L., Sternson, S.M., 2011. Chemical and genetic engineering of selective ion channel-ligand interactions. Science 333, 1292-1296. https://doi.org/10.1126/science.1206606.

Magnus, C.J., Lee, P.H., Bonaventura, J., Zemla, R., Gomez, J.L., Ramirez, M.H., Hu, X., Galvan, A., Basu, J., Michaelides, M., Sternson, S.M., 2019. Ultrapotent chemogenetics for research and potential clinical applications. Science 364. https://doi.org/ 10.1126/science.aav5282.

Manvich, D.F., Webster, K.A., Foster, S.L., Farrell, M.S., Ritchie, J.C., Porter, J.H., Weinshenker, D., 2018. The DREADD agonist clozapine N-oxide (CNO) is reversemetabolized to clozapine and produces clozapine-like interoceptive stimulus effects in rats and mice. Sci. Rep. 8, 3840. https://doi.org/10.1038/s41598-018-22116-z.

Miles, R., Blaesse, P., Huberfeld, G., Wittner, L., Kaila, K., 2012. Chloride homeostasis and GABA signaling in temporal lobe epilepsy. In: Noebels, J.L., Avoli, M., Rogawski, M.A., Olsen, R.W., Delgado-Escueta, A.V. (Eds.), Jasper's Basic Mechanisms of the Epilepsies. National Center for Biotechnology Information (US), Bethesda (MD).

Morrell, M.J., RNS System in Epilepsy Study Group, 2011. Responsive cortical stimulation for the treatment of medically intractable partial epilepsy. Neurology 77, 1295-1304. https://doi.org/10.1212/WNL.0b013e3182302056.

Nagel, G., Szellas, T., Huhn, W., Kateriya, S., Adeishvili, N., Berthold, P., Ollig, D., Hegemann, P., Bamberg, E., 2003. Channelrhodopsin-2, a directly light-gated cationselective membrane channel. Proc. Natl. Acad. Sci. 100, 13940-13945. https://doi. org/10.1073/pnas.1936192100.

Noè, F., Pool, A.-H., Nissinen, J., Gobbi, M., Bland, R., Rizzi, M., Balducci, C., Ferraguti, F., Sperk, G., During, M.J., Pitkänen, A., Vezzani, A., 2008. Neuropeptide Y gene therapy decreases chronic spontaneous seizures in a rat model of temporal lobe epilepsy. Brain 131, 1506-1515. https://doi.org/10.1093/brain/awn079.

Olanow, C.W., 2014. Parkinson disease: gene therapy for Parkinson disease-a hope, or a dream? Nat. Rev. Neurol. 10, 186-187. https://doi.org/10.1038/nrneurol.2014.45.

Owen, S.F., Liu, M.H., Kreitzer, A.C., 2019. Thermal constraints on in vivo optogenetic manipulations. Nat. Neurosci. 22, 1061-1065. https://doi.org/10.1038/s41593-0190422-3.

Paz, J.T., Davidson, T.J., Frechette, E.S., Delord, B., Parada, I., Peng, K., Deisseroth, K., Huguenard, J.R., 2013. Closed-loop optogenetic control of thalamus as a tool for interrupting seizures after cortical injury. Nat. Neurosci. 16, 64-70. https://doi.org/ 10.1038/nn.3269.

Romano, G., 2006. Advances and perspectives in the field of gene transfer technology. Drug News Perspect. 19, 359-368.

Ruffmann, C., Bogliun, G., Beghi, E., 2006. Epileptogenic drugs: a systematic review. Expert Rev. Neurother. 6, 575-589. https://doi.org/10.1586/14737175.6.4.575.

Saloman, J.L., Scheff, N.N., Snyder, L.M., Ross, S.E., Davis, B.M., Gold, M.S., 2016. Gidreadd expression in peripheral nerves produces ligand-dependent analgesia, as well as ligand-independent functional changes in sensory neurons. J. Neurosci. 36, 10769-10781. https://doi.org/10.1523/JNEUROSCI.3480-15.2016.

Sammaraiee, Y., Yardley, M., Keenan, L., Buchanan, K., Stevenson, V., Farrell, R., 2019. Intrathecal baclofen for multiple sclerosis related spasticity: a twenty year experience. Mult Scler Relat Disord 27, 95-100. https://doi.org/10.1016/j.msard.2018.10. 009.

Semah, F., Picot, M.C., Adam, C., Broglin, D., Arzimanoglou, A., Bazin, B., Cavalcanti, D., Baulac, M., 1998. Is the underlying cause of epilepsy a major prognostic factor for recurrence? Neurology 51, 1256-1262. https://doi.org/10.1212/wnl.51.5.1256.

Sessolo, M., Marcon, I., Bovetti, S., Losi, G., Cammarota, M., Ratto, G.M., Fellin, T., Carmignoto, G., 2015. Parvalbumin-positive inhibitory interneurons oppose propagation but favor generation of focal epileptiform activity. J. Neurosci. 35, 
9544-9557. https://doi.org/10.1523/JNEUROSCI.5117-14.2015.

Simonato, M., Bennett, J., Boulis, N.M., Castro, M.G., Fink, D.J., Goins, W.F., Gray, S.J., Lowenstein, P.R., Vandenberghe, L.H., Wilson, T.J., Wolfe, J.H., Glorioso, J.C., 2013. Progress in gene therapy for neurological disorders. Nat. Rev. Neurol. 9, 277-291. https://doi.org/10.1038/nrneurol.2013.56.

Slimko, E.M., McKinney, S., Anderson, D.J., Davidson, N., Lester, H.A., 2002. Selective electrical silencing of mammalian neurons in vitro by the use of invertebrate ligandgated chloride channels. J. Neurosci. 22, 7373-7379. https://doi.org/10.1523/ JNEUROSCI.22-17-07373.2002.

Snowball, A., Chabrol, E., Wykes, R.C., Shekh-Ahmad, T., Cornford, J.H., Lieb, A., Hughes, M.P., Massaro, G., Rahim, A.A., Hashemi, K.S., Kullmann, D.M., Walker M.C., Schorge, S., 2019. Epilepsy gene therapy using an engineered potassium channel. J. Neurosci. 39, 3159-3169. https://doi.org/10.1523/JNEUROSCI.1143-18. 2019.

Sørensen, A.T., Ledri, M., Melis, M., Nikitidou Ledri, L., Andersson, M., Kokaia, M., 2017. Altered chloride homeostasis decreases the action potential threshold and increases hyperexcitability in hippocampal neurons. eNeuro 4. https://doi.org/10.1523/ ENEURO.0172-17.2017.

Stavarache, M.A., Petersen, N., Jurgens, E.M., Milstein, E.R., Rosenfeld, Z.B., Ballon, D.J., Kaplitt, M.G., 2018. Safe and stable noninvasive focal gene delivery to the mammalian brain following focused ultrasound. J. Neurosurg. 130, 989-998. https://doi. org/10.3171/2017.8.JNS17790.

Tønnesen, J., Sørensen, A.T., Deisseroth, K., Lundberg, C., Kokaia, M., 2009. Optogenetic control of epileptiform activity. Proc. Natl. Acad. Sci. U.S.A. 106, 12162-12167. https://doi.org/10.1073/pnas.0901915106.

Tracy, J.I., Doucet, G.E., 2015. Resting-state functional connectivity in epilepsy: growing relevance for clinical decision making. Curr. Opin. Neurol. 28, 158-165. https://doi. org/10.1097/WCO.0000000000000178.

Wacker, D., Stevens, R.C., Roth, B.L., 2017. How ligands illuminate GPCR molecular pharmacology. Cell 170, 414-427. https://doi.org/10.1016/j.cell.2017.07.009.

Wang, Ying, Liang, J., Chen, L., Shen, Y., Zhao, J., Xu, C., Wu, X., Cheng, H., Ying, X., Guo, Y., Wang, S., Zhou, Y., Wang, Y.I., Chen, Z., 2018. Pharmaco-genetic therapeutics targeting parvalbumin neurons attenuate temporal lobe epilepsy. Neurobiol. Dis. 117, 149-160. https://doi.org/10.1016/j.nbd.2018.06.006.

Wess, J., Nakajima, K., Jain, S., 2013. Novel designer receptors to probe GPCR signaling and physiology. Trends Pharmacol. Sci. 34, 385-392. https://doi.org/10.1016/j.tips. 2013.04.006.

Weston, M., Kaserer, T., Wu, A., Mouravlev, A., Carpenter, J.C., Snowball, A., Knauss, S., von Schimmelmann, M., During, M.J., Lignani, G., Schorge, S., Young, D., Kullmann,
D.M., Lieb, A., 2019. Olanzapine: a potent agonist at the hM4D(Gi) DREADD amenable to clinical translation of chemogenetics. Sci Adv 5 eaaw1567. https://doi. org/10.1126/sciadv.aaw1567.

Wicker, E., Forcelli, P.A., 2016. Chemogenetic silencing of the midline and intralaminar thalamus blocks amygdala-kindled seizures. Exp. Neurol. 283, 404-412. https://doi. org/10.1016/j.expneurol.2016.07.003.

Wiechert, P., Herbst, A., 1966. Provocation OF cerebral seizures BY derangement OF the natural balance between glutamic acid and $\gamma$-AMINOBUTYRIC acid. J. Neurochem. 13, 59-64. https://doi.org/10.1111/j.1471-4159.1966.tb03332.x.

Wilson, J.M., 2009. Lessons learned from the gene therapy trial for ornithine transcarbamylase deficiency. Mol. Genet. Metab. 96, 151-157. https://doi.org/10.1016/j. ymgme.2008.12.016.

Woldbye, D.P.D., Angehagen, M., Gøtzsche, C.R., Elbrønd-Bek, H., Sørensen, A.T., Christiansen, S.H., Olesen, M.V., Nikitidou, L., Hansen, T.V.O., Kanter-Schlifke, I., Kokaia, M., 2010. Adeno-associated viral vector-induced overexpression of neuropeptide Y Y2 receptors in the hippocampus suppresses seizures. Brain 133, 2778-2788. https://doi.org/10.1093/brain/awq219.

Wykes, R.C., Heeroma, J.H., Mantoan, L., Zheng, K., MacDonald, D.C., Deisseroth, K., Hashemi, K.S., Walker, M.C., Schorge, S., Kullmann, D.M., 2012. Optogenetic and potassium channel gene therapy in a rodent model of focal neocortical epilepsy. Sci. Transl. Med. 4 161ra152. https://doi.org/10.1126/scitranslmed.3004190.

Yaguchi, M., Ohashi, Y., Tsubota, T., Sato, A., Koyano, K.W., Wang, N., Miyashita, Y., 2013. Characterization of the properties of seven promoters in the motor cortex of rats and monkeys after lentiviral vector-mediated gene transfer. Hum. Gene Ther Methods 24, 333-344. https://doi.org/10.1089/hgtb.2012.238.

Yáñez-Muñoz, R.J., Balaggan, K.S., MacNeil, A., Howe, S.J., Schmidt, M., Smith, A.J., Buch, P., MacLaren, R.E., Anderson, P.N., Barker, S.E., Duran, Y., Bartholomae, C., Kalle, C., Heckenlively, J.R., Kinnon, C., Ali, R.R., Thrasher, A.J., 2006. Effective gene therapy with nonintegrating lentiviral vectors. Nat. Med. 12, 348. https://doi.org/10. $1038 / \mathrm{nm} 1365$.

Zhang, F., Wang, L.-P., Brauner, M., Liewald, J.F., Kay, K., Watzke, N., Wood, P.G., Bamberg, E., Nagel, G., Gottschalk, A., Deisseroth, K., 2007. Multimodal fast optical interrogation of neural circuitry. Nature 446, 633-639. https://doi.org/10.1038/ nature05744.

Zhou, Q.-G., Nemes, A.D., Lee, D., Ro, E.J., Zhang, J., Nowacki, A.S., Dymecki, S.M., Najm, I.M., Suh, H., 2019. Chemogenetic silencing of hippocampal neurons suppresses epileptic neural circuits. J. Clin. Investig. 129, 310-323. https://doi.org/10. 1172/JCI95731. 